AAM under the Creative Commons Attribution Non-commercial International Licence 4.0 (CC BY-NC 4.0)

\title{
Embedding and managing blockchain in sustainability reporting: A practical framework
} Accepted for publication in Sustainability Accounting, Management and Policy Journal

ISSN: 2040-8021

DOI: 10.1108/SAMPJ-07-2021-0288

Authors:

Simone Pizzi ${ }^{\mathrm{a}}$

${ }^{a}$ Dipartimento di Scienze dell’Economia, University of Salento, Lecce, Italy, simone.pizzi@,unisalento.it

\section{Andrea Caputo ${ }^{\mathrm{b}, \mathrm{c}}$}

${ }^{\mathrm{b}}$ Department of Economics \& Management, University of Trento, Trento, Italy, andrea.caputo@unitn.it

c Lincoln International Business School, University of Lincoln, United Kingdom, acaputo@lincoln.ac.uk

Andrea Venturelli ${ }^{\mathrm{a}}$

a Dipartimento di Scienze dell'Economia, University of Salento, Lecce, Italy, andrea.venturelli@unisalento.it

Fabio Caputo $^{\mathrm{a}}$

a Dipartimento di Scienze dell’Economia, University of Salento, Lecce, Italy, fabio.caputo@unisalento.it

Corresponding author:

Simone Pizzi ${ }^{\mathrm{a}}$

a Dipartimento di Scienze dell’Economia, University of Salento, Lecce, Italy, simone.pizzi@unisalento.it 


\title{
Embedding and managing blockchain in sustainability reporting: A practical framework
}

\begin{abstract}
Purpose: The purpose of this paper consists in the evaluation of blockchain's enabling role for sustainability reporting. The study extends the scientific knowledge about the impacts related to the notarization of mandatory sustainability reports through a publicly available blockchain.

Design/methodology/approach: Building on the Idea Journey Framework, the paper presents the case study of Banca Mediolanum in Italy, a first-mover who notarized its non-financial declaration on a public blockchain to mitigate the information asymmetries that negatively impact stakeholder engagement.
\end{abstract}

Findings: The analysis reveals that the notarization of the non-financial reports through a publicly available blockchain can represent a tool useful to mitigate the asymmetric information between organizations and stakeholders.

Originality: To the best of our knowledge, this is the first study about sustainability reporting practices and blockchain. This research contributes to the currently scarce discussion about the role of blockchain in nonfinancial reporting. In addition, we contribute to the scientific conversation about the need to rethink assurance in non-financial reporting practices.

Practical implications: Although academics and practitioners have observed the benefits of its implementation, only a few companies have adopted blockchain systems to ensure their information's reliability. Our findings underline the opportunity for socially responsible organizations to signal their orientation toward sustainable development through the adoption of an innovative tool.

\section{Keywords}

Blockchain, notarization, trust, audit, sustainability reporting

\section{Introduction}

In recent years, non-financial reports that are either voluntary or mandatory have proliferated (KPMG, 2017). This quantitative increase is followed by a qualitative increase in the information required by stakeholders (IFAC, 2019). Compared to previous years, stakeholders have shown greater interest in evaluating firms' contributions to sustainable development. These trends are also influencing the academic debate towards a reflection about the market value of a business as an accurate measure of shareholder welfare (e.g., Hart and Zingales, 2017). Whilst non-financial reports should serve as incentives for sustainable managerial behaviours, their proliferation also represents a paradoxical phenomenon due to the opportunistic behaviours adopted by some managers (Diouf and Boiral, 2017). For example, many environmental scandals have been characterised by the adoption of greenwashing or impression management strategies (Plec and Pettenger, 2012; Siano et al., 
2017). This trend continues, as exemplified by the recent collapse of the German fintech company, Wirecard AG, following a financial scandal unveiled by an investigation from the Financial Times (Storbeck and McCrum, 2020).

In Europe, the proliferation of non-financial reporting practices has been driven by the European Member States' transposition of the Directive 2014/95/EU. The Directive 2014/95/EU is the first attempt made by the European Commission (EC) to encourage large organisations to disclose their non-financial information. Since its first introduction, the EC has extended and revised its contents to enhance its effectiveness. The first intervention in 2017 involved the Commission Communication 2017/C215/01 and the guidelines for the presentation of non-financial reports. In detail, the EC published specific guidelines that favoured the adoption of common reporting guidelines by European public interest entities (PIEs). However, a few years after its transposition, the Directive 2014/95/EU has been subjected to relevant changes connected by the EC's intention to standardise the contents of non-financial declarations. Thus, the European context represents an institutional context characterised by an increasing awareness about sustainability reporting.

However, non-financial information disclosure is unable to represent a true orientation towards sustainable practices (Dumay et al., 2015). In fact, prior studies have validated the limited effects of the transposition of the Directive 2014/95/EU (Pizzi, Venturelli, et al., 2021). Thus, it has now become apparent how accounting practices' harmonization generated by non-financial regulation does not prove real organisational and strategic changes amongst firms (Adams and Narayanan, 2010). Prior studies on non-financial reporting quality have offered explanations for the limited effects of the Directive 95/2014/EU's introduction in Europe. For example, Bebbington et al. (2012) underlined that legal provisions do not favour the transition to more sustainable practices. Ackers and Eccles (2015) observed the widespread adoption of a 'tick-box' approach by South African firms affected by King Code III, which explicitly required them to disclose mandatory information about non-financial impacts. Another factor limiting the effects of the Directive 95/2014/EU comes from the wide adoption of voluntarily prepared non-financial declarations (NFDs) by PIEs before the transposition of the Directive (Doni et al., 2019). Recently, the EC (2020) has begun to discuss revisions to the Directive 95/2014/EU to ensure higher degrees of transparency. Indeed, although NFDs are a proxy of the social and environmental orientation of PIEs, the Directive 95/2014/EU has been introduced to provide further necessary information to financial stakeholders.

The broad diffusion of reports prepared on a mandatory basis requires a reflection about the relationship between non-financial information and trust. In particular, the mandatory provision limits the signalling effects of non-financial reports (Dumay et al., 2015) and assurance practices (Sheldon and Jenkins, 2020). In the European context, the signalling effect of third-party independent assurance statements has been limited by the Directive 95/2014/EU. In addition, European PIEs' adoption of different assurance standards (e.g. ISAE 3000, AA1000AS) has also limited information transparency (Venturelli and Pizzi, 2020). Thus, preparers and standard setters have begun to discuss new methods to increase non-financial reporting transparency. 
In this regard, blockchain represents one of the main innovations identified by academics to enhance transparency (Bible et al., 2017). In particular, it contributes to the achievement of a highest degree of accuracy and traceability (Hinkes and Peter, 2020; Hughes et al., 2019). However, implementing a blockchain system in accounting and auditing remains a complex undertaking due to organisational barriers caused by a lack of knowledge regarding its potential (Dai and Vasarhelyi, 2017). Dai and Vasarhely highlighted that blockchain's adoption is limited by the existence of barriers related to technological, organisational and environmental dynamics. The current debate is characterised by only a few studies about blockchain's integration in accounting and auditing processes (Mancini et al., 2021). Thus, bridging the knowledge gap between theory and praxis represents a task characterised by a high degree of complexity due to the overall lack of evidencebased research about its adoption.

The current paper aims to contribute to the existing debate about blockchain's adoption in accounting and auditing practices through a longitudinal case study. In particular, this work aims to fill the knowledge gap about blockchain's adoption in sustainability reporting, which represents an independent topic in accounting research. The choice to pay specific attention to sustainability reporting was driven by the opportunity to extend a specific research field characterised by a limited number of theoretical contributions (Mancini et al., 2021). In particular, the present paper fills the specific scientific gap highlighted by Unerman et al. (2018) regarding the enabling role played by blockchain in non-financial information transparency. In fact, despite the increasing attention from academics, only a few studies have empirically analysed the potential impacts of blockchain on non-financial reporting (Di Vaio and Varriale, 2020; de Villiers et al., 2020).

Following the Idea Journey framework proposed by Perry-Smith and Mannucci (2017), we will evaluate the innovative approach to non-financial reporting initiated by the leading Italian bank, Banca Mediolanum. This bank was chosen for analysis, as it offers the opportunity to evaluate a first mover in blockchain application in non-financial accounting and auditing. Despite mandatory external assurance, the bank has been one of the first companies in the world to notarise its non-financial reports on Ethereum, one of the main decentralised open source blockchains. In addition, Banca Mediolanum plays a pivotal role in the debate over introducing distributed ledger technology (DLT) within the Italian banking system. This study has a qualitative nature, and it is based on various sources, such as an interview with the Head of Blockchain for Banca Mediolanum. The direct interview is research method that is particularly suitable for accounting studies characterised by the need to evaluate the specificities of the case through an in-depth approach (Tucker, 2020). Furthermore, we considered the information included within NFDs, videos and articles to integrate our analysis (Al-Htaybat and von Alberti-Alhtaybat, 2018; Martin-Sardesai and Guthrie, 2020).

The paper is structured as follows. Section 2 analyses previous research on blockchain systems in accounting and auditing. In Sections 3 and 4, we discuss our theoretical framework and describe our methodological approach, respectively. Section 5 highlights the main findings collected, whilst Section 6 provides a detailed discussion of our theoretical and managerial implications. Finally, Section 7 summarises the main reflections about blockchain's integration into sustainability reporting. 


\section{Literature review}

\subsection{Blockchain and transparency}

Financial and business dynamics are characterised by complexities caused by the existence of opportunistic behaviours and information asymmetries between the parties involved (Lumineau and Oliveira, 2017; March, 1987). These criticisms favoured the rapid growth of a new research area inspired by the opportunity to contribute to the debate through practical and theoretical insights. However, recent corporate scandals highlighted the fact that, even in the presence of best practices, corporate misconducts and opportunistic behaviours are two emerging phenomena characterised by a high degree of risks due to non-identification (Siano et al., 2017; Storbeck and McCrum, 2020). Thus, the last years have been characterised by an increasing awareness by academics about the need to explore the enabling role played by emerging technologies and strategies to mitigate these risks (Chiu et al., 2019).

In this regard, blockchain has become one of the main topics discussed by academics (Lombardi et al., 2021). First conceptualised by Nakamoto (2008), blockchain represents a disruptive technological innovation that has been widely explored by policymakers, academics and practitioners due to its originality and uniqueness. In detail, blockchain is a distributed ledger technology based on an ongoing chain of hash-based proof-of-work, which represents a record characterised by non-repudiability and non-modifiability. Thus, it is considered an effective approach to mitigating the risks related to false or untruly information and enhancing trust between parties (Nakamoto, 2008).

Blockchain technology was initially used to develop cryptocurrencies due to the security, transparency and certainty of the system of transactions (Tandon et al., 2021). These characteristics have subsequently favoured the adoption of blockchain-based technologies to navigate other trust relationships in other business areas, such as supply chains, accounting and auditing (Dai and Vasarhelyi, 2017; Wang et al., 2019). In this context, blockchain enables the validation of contracts or information in the web of relationships between suppliers and clients or investors (Wamba and Queiroz, 2020).

Nowadays, the development of an adequate level of transparency is limited by the need to involve third-party intermediaries within a firm's operations (Cai, 2018). External auditors are the main intermediaries when considering non-financial reporting (Simnett et al., 2015). However, such external auditing activities include transaction costs to manage the uncertainty (Ahluwalia et al., 2020). Despite the differences in various possible uses of blockchain, a common success factor is the guarantee of adequate transparency and the perceived impossibility of meddling with the information included in the ledger. Thus, blockchain is considered a strategic asset for globally competitive business enterprises due to its potential positive effects on stakeholders' trust (Sheel and Nath, 2019).

\subsection{Blockchain in accounting and auditing}

In both the accounting and auditing fields, legal, technical and social barriers can restrict technological innovations. In particular, the need to comply with laws and regulations can limit or slow down the adoption 
of new technologies (Ackers and Eccles, 2015). Several studies have examined the effects of regulations on the adoption of new digital features in non-financial reporting. For example, a recent bibliometric study highlighted the limited adoption of the XBRL technology in non-financial reporting activities, despite being available for over 20 years (Bartolacci et al., 2020). Further insights into the barriers to the adoption of digital features have been provided by Cordery et al. (2011) and Stubbs and Higgins (2018), who reported the existence of cultural barriers related to the absence of interest in digitalising operations without pressure from regulators.

In recent years, an increasing number of academics have initiated conversations discussing how blockchain can enhance stakeholder trust (Donohue, 2018; Schmitz and Leoni, 2019). Blockchain's key impacts can be observed on operations that feature highly asymmetric information between preparers and stakeholders, such as accounting and auditing practices. In particular, Dai and Vasarhelyi (2017) highlighted that blockchain could increase the transparency of such practices through the provision of accounting information systems that record validated transactions on secure ledgers. Thus, the transparency of the information disclosed in a regulated context can increase through the provision of a 'double' assurance via the notarisation of the information on an open-access database. Furthermore, Karajovic et al. (2019) stated that blockchain's future impact will be disruptive for accountants, as it would require them to rethink their activities in accordance with a new organisational paradigm based on automation.

However, according to the latest survey conducted by the auditing firm PricewaterhouseCoopers (PWC), blockchain's integration within organisations is limited by several factors, such as a lack of trust in the absence of regulation and the difficulty of involving third parties in internal processes (PWC, 2018). Thus, despite external pressures from stakeholders, the adoption of blockchain systems still requires firms and third parties to embrace this paradigm shift.

\section{Theoretical framework}

\subsection{Legitimacy theory and the Directive 2014/95/EU}

Prior studies have highlighted that regulation is the primary driver of the standardisation of non-financial reports (La Torre et al., 2018; Venturelli and Pizzi, 2020). However, regulation does not necessarily increase the adoption of voluntary practices in a way that improves the qualitative degree of information provided to stakeholders, as confirmed by prior studies on the Directive 95/2014/EU. In particular, previous results highlighted that NFDs' transparency is influenced by the sector of origin and prior expertise in non-financial reporting practices (Doni et al., 2019; Nicolo et al., 2020). Yet, other studies have recorded criticisms in response to the Directive's one-size-fits-all approach. For instance, Pizzi et al. (2020) posited that NFDs prepared by Italian PIEs have been impacted by the wide adoption of a comply-or-explain approach, which avoids the negative effects caused by the disclosure of unfavourable information. Another critical perspective has been provided by the findings of Di Tullio et al. (2019) on the different accounting strategies used to disclose information about business models. In particular, they found that organisations disclosed their business models in both financial and non-financial reports. The level of information disclosed within NFDs 
is influenced by the preparers' orientation towards non-financial reporting practices. Finally, Dumay et al. (2019) underlined the importance of evolving from a quantitative to a qualitative approach to NFDs.

Meanwhile, the lack of transparency in NFDs limits the effective comprehension of the non-financial activities conducted by European PIEs. However, the provision of mandatory assurance cancels out the signalling effects of an external verification made by independent auditors. The marketisation of non-financial assurance practices has reduced the useful information provided by such assurance due to the increasing adoption of restatements required by auditors to legitimise their role (Sheldon and Jenkins, 2020). Furthermore, the Directive 95/2014/EU allows preparers to comply with the national law through the adoption of integrated reports; however the reliability of these reports is limited by the absence of assurance standards (Venturelli and Pizzi, 2020).

As a result, the voluntary adoption of innovative communication and assurance strategies can be a way to increase non-financial reports' transparency, where firms may compete for a 'transparency advantage' by signalling to investors and stakeholders their adherence to a stricter set of disclosure practices. The benefits related to the implementation of innovative and unconventional accountability practices have been widely explored by accounting academics. Moreover, in the past few years, academics have analysed the phenomenon through the lens of the legitimacy theory proposed by DiMaggio and Powell (1983). Starting from the concept of isomorphism, these authors underlined the need for elite companies to constantly monitor their processes to avoid risks related to the isomorphic strategies adopted by competitors. Such evidence is directly related to the effects brought about by the introduction of non-financial reporting regulation in an institutional context, which is characterised by the coexistence of early adopters and latecomers (Corvino et al., 2020; La Torre et al., 2020). In fact, despite the positive externalities related to the introduction of specific rules about non-financial reporting, many academics have reiterated the existence of different effects related to the transposition of the Directive 2014/95/EU. In particular, the theoretical debate distinguishes between the effects on latecomers and early adopters (Korca et al., 2021). On the one hand, the Directive 2014/95/EU can become a disruptive innovation for latecomers who do not have any experience in sustainability reporting (Caputo et al., 2019; Doni et al., 2019). On the other hand, early adopters are interested in critical issues related to the need to signal their orientation towards sustainable development through alternative forms of accountability (Pizzi, Rosati, et al., 2021).

According to this evidence, integrating blockchain into sustainability reporting could become an emerging and novel practice characterised by a high degree of complexity. Thus, evaluating blockchain's adoption requires the use of a multidimensional approach based on the analysis of the managerial and technological implications related to its implementation (Durocher et al., 2007; Sutton et al., 2011). In particular, the analysis was built through the combination of theoretical propositions proposed by Perry-Smith and Mannucci (2017) and Saberi et al. (2019).

\subsection{The Idea Journey Framework}


The idea journey framework was first proposed by Perry-Smith and Mannucci (2017). Initially developed for the creativity industries, the framework has since been widely used by academics to evaluate the dynamics of innovations introduced within business processes. According to the authors, the Idea Journey Framework represents a methodological approach suitable identify a pathway that could inform "how and when a novel idea either successfully moves through the entire journey, ultimately changing the field, or gets "stuck" in any one phase or loop between phases' (Perry-Smith and Mannucci, 2017, p. 54). In particular, Perry-Smith and Mannucci (2017) suggested that firms' development of innovative practices occurs through four independent phases, which begin with idea generation and finish with implementation.

The idea journey framework's relevance for accounting scholars was underlined by Rinaldi et al. (2018), who stated that the adoption of this framework 'can be used to shape and add coherence to accounting research'. Starting from a theoretical evaluation of the scientific debate on integrated reporting, Rinaldi and colleagues highlighted that the Idea Journey Framework represents a theoretical framework useful to identify scientific gaps and to create new understanding about accounting practices. Another contribution was provided by Martin-Sardesai and Guthrie (2020), who used the model to evaluate the evolution of social reporting practices in a large Italian bank. Their findings included insights into the evolutionary approach adopted by organisations to create practices that respond to internal and external pressures from stakeholders.

The first phase of the idea journey framework consists of idea generation. Whilst there has been rapid growth in recent years, non-financial reporting activities are usually perceived as voluntary practices. The proliferation of non-financial reports has been favoured by the introduction of new forms of regulations, such as the Directive 95/2014/EU and the King Code III (Ackers and Eccles, 2015; Pizzi, Venturelli, et al., 2021). In particular, the Directive 95/2014/EU has led to the diffusion of non-financial reporting practices due to the absence of regulations on socially responsible themes (Steurer et al., 2012). However, the provision of regulations has negatively impacted non-financial reporting quality. As observed by several authors, the NFDs prepared on a mandatory basis in the first few years after the transposition of the Directive 95/2014/EU show a different quality than their predecessors (Doni et al., 2019; Nicolo et al., 2020). Thus, the identification of voluntary disclosure is an innovative approach due to the absence of incentives for disclosing information through alternative forms of reporting.

The next phase, idea elaboration, can be quite complex when applied to non-financial reporting practices. The sources of complexity include the central role play by international standard setters, such as the Global Reporting Initiative, the IIRC and the UN Global Compact. A survey conducted by Deloitte (2019b) highlighted the fact that despite the opportunity for PIEs to self-identify any reporting standard, all the Italian PIEs adopted the GRI as their reporting standard. Similar standardised approaches have been employed in other contexts, such as South Africa (Ackers and Eccles, 2015). Another limit to idea elaboration is the high degree of standardisation regarding auditing practices. In particular, many of the largest European PIEs assured their reports through ISAE 3000 (Venturelli and Pizzi, 2020). Despite the provision to combine ISAE 3000 with additional auditing standards, such as AA1000 or ISAE 3410, European PIEs have not experimented with 
alternative forms of assurance practices. Given this situation, the elaboration of an innovative idea in nonfinancial auditing and accounting practices remains a challenge for preparers and auditors.

Before initiating the processes related to the revision of the Directive 2014/95/EU, the only substantial innovation proposed by the EC was the amendment on climate change reporting (EC, 2019). Thus, opportunities to champion new ideas - the third phase of the idea journey framework - have been limited due to the absence of public consultation. The revision of the Directive 95/2014/EU represents an opportunity for practitioners, think tanks and non-governmental organisations (NGOs) to share their ideas to be considered and possibly legitimised by European regulators. In fact, firms are discouraged from championing their ideas due to the high degree of bureaucratisation caused by regulation. Proposing a new idea in mandatory nonfinancial reporting practices cannot be achieved without external verification from a regulator. This has been confirmed by the survey conducted by The Alliance for Corporate Transparency (2020) on 1000 European PIEs affected by the Directive 95/2014/EU. These organisations revealed that voluntary topics, such as digitalisation, data protection and resource use, have been scarcely analysed. Furthermore, only a few business enterprises have adopted innovative reporting standards, such as the Sustainability Accounting Standard Board (SASB) guidelines. Little experimentation has also been done by PIEs in the first five years after the introduction of the Directive 95/2014/EU.

Finally, the idea journey framework's last phase can be divided into idea production and idea impact (PerrySmith and Mannucci, 2017). This distinction is made to analyse two different time periods. Idea production consists of the activities implemented to introduce a new product or service within the market, whilst idea impact involves the follow-up evaluation of its effect in the market. In non-financial reporting practices, those two phases can be compared to the early adoption of non-financial reporting prepared on a mandatory basis. The first insights about the Directive 95/2014/EU confirms that the first movers are typically more socialresponsibility-oriented than late adopters. In particular, prior studies on non-financial reporting quality in Italy have shown agreement that the early adopters' NFDs were more informative than those of late adopters (Doni et al., 2019; Pizzi, Venturelli, et al., 2021). The main lesson learned about the Directive 2014/95/EU seems to be a need to rethink its contents to evolve from a one-size-fits-all approach to a more innovative view that encourages the adoption of alternative practices by practitioners and managers.

\subsection{Blockchain's barriers}

Evaluating and comprehending the barriers to the adoption of blockchain systems in sustainable practices represents a novel field of study. In recent years, several authors have started to conceptualize the main constraints and opportunities related to the adoption of these practices by companies (Lombardi et al., 2021; de Villiers et al., 2020).

Thus far, some academics and practitioners agree on the existence of barriers that negatively impact the adoption of blockchain systems (Deloitte, 2019b; Helliar et al., 2020). Such barriers are mainly related to managers' technological resistance and lack of knowledge about blockchain's potential (Tapscott and 
Tapscott, 2016). Furthermore, specific barriers related to accounting and auditing processes have been identified. For example, Dai and Vasarhelyi (2017b) highlighted that blockchain's implementation in accounting and auditing is limited by the existence of three different types of barriers: a) technological, b) organisational and c) environmental contexts. Thus, the implementation of processes based on blockchain is expected to be a highly complex task for companies interested in integrating it to their business operations (Wong et al., 2020).

Saberi et al. (2019) proposed a first attempt to conceptualise the main barriers to blockchain integration in sustainable practices by analysing the most relevant articles about supply chain information systems, sustainable supply chains and blockchain technology. Furthermore, to ensure the reliability of the analysis, they integrated their insights through the direct involvement of blockchain experts. They identified four categories of barriers: intra-organisational, inter-organisational, system-related and external barriers (Table 2).

\section{Please Insert Table 2}

\section{Research designs}

\subsection{Methods}

Evaluating an emerging topic in accounting research has been a major challenge for accounting scholars. In the last few years, many academics have underlined the relevance of qualitative methods in accounting studies (Hoque, 2018; Sandberg et al., 2020). In particular, qualitative methods are considered effective tools that can contribute to the understanding and critiquing of management and accounting processes as well as addressing the concerns of practitioners and policymakers (Parker, 2012). Furthermore, qualitative methods allow researchers to extend current scientific knowledge through the identification of original insights into complex and rare phenomena (Hoque, 2018, p. 499).

Building on this preliminary evidence, qualitative methods facilitate the comprehension of a complex and novel phenomenon, such as the implementation of blockchain systems in accounting practices (Bible et al., 2017; Lombardi et al., 2021; Schmitz and Leoni, 2019). In addition, non-financial reporting practices represent a subfield of accounting studies and professions. In this sense, the implementation of blockchain in nonfinancial reporting differs from traditional financial reporting practices.

The current research was conducted using inductive theory building based on a descriptive case study (Yin, 2012). This is a methodological approach adopted by accounting scholars to describe complex phenomena in their real-life contexts (Hoque, 2018, p. 488). Case studies offer both interpretive and critical understandings of the social and institutional nature of organisational processes and management accounting practices (Parker, 2012, p. 57). Furthermore, it represents one of the main research methods adopted by accounting scholars who are interested in evaluating managerial accounting practices through qualitative and critical lenses (Lee and Humphreys, 2017). 
The development of a case study requires the identification of a clear research protocol (Yin, 2012). Thus, in the following sections, we will describe the case, the data collection and the theoretical approach used to evaluate our insights.

\subsection{The case: Banca Mediolanum}

This research was conducted on a single case study, which is a methodological approach that is particularly suitable for extreme or unique cases (Yin, 2018, p.84). This case is distinct (Yin, 2018, p. 84) because of the notarisation of the NFDs on Ethereum. In this sense, the adoption of a blockchain system to notarise a document, which is assured by an independent third party, represents a first attempt to raise the bar for nonfinancial reporting transparency (Forbes, 2019).

Banca Mediolanum (hereafter referred to as 'Mediolanum') is one of the largest financial institutions in Italy. Founded in 1997, the bank based its competitive advantage on developing strategies to reduce the gap between the institution and its stakeholders over the years. Indeed, enhancing stakeholders' trust is the main goal of Mediolanum, as evidenced by its motto: 'The bank built around you'.

Stakeholders' centrality is also confirmed by the CEO's letters included in the NFDs published by the bank. Throughout the years, Mediolanum has adopted an innovative approach to engage effectively with stakeholders. In fact, although a principle-based approach inspires European regulation on mandatory nonfinancial reporting, Mediolanum has increased its external commitments each year.

Mediolanum's non-financial reporting approach is not merely to adopt the minimum requirements to comply with the law. Since the first year after the transposition of the Directive 2014/95/EU, NFDs were prepared in according to the latest guidelines released by the Global Reporting Initiative whilst the assurance was conducted by a Big4 in accordance with the ISAE 3000. Furthermore, in 2019, Mediolanum included explicit reference to the SDGs and to the TFCD, which are considered the best practices in the accounting field. Thus far, the effects of the regulation on Mediolanum have been limited, because the group has published nonfinancial reports since 2006. Thus, the bank is considered as a first mover within a context characterised by a high degree of bureaucratisation and lack of knowledge regarding non-financial reporting. Finally, since 2016, Mediolanum has published a digital version of its non-financial reports on YouTube (Mediolanum, 2021).

\subsection{Data collection}

Similar to prior studies on non-financial reporting in the banking sector (Al-Htaybat and von Alberti-Alhtaybat, 2018; Liff and Wahlström, 2018; Martin-Sardesai and Guthrie, 2020), the current analysis has been conducted through primary and secondary data. Furthermore, different sources have been adopted to achieve the highest degree of validity and triangulation of our data analysis (Yin, 2018; p.49).

Regarding the primary data used in the paper, the Head of Blockchain of Banca Mediolanum was involved in the research. This source was used to collect specific and technical information about Mediolanum's blockchain operations and strategies. The data were collected through interviews - a common methodological 
approach used by management scholars to analyse managerial accounting practices (Tucker, 2020). In detail, we conducted two virtual interviews lasting an hour each to collect specific information about the evolutionary pathway adopted by Mediolanum to integrate blockchain in its processes. For our purposes, we adopted a methodological approach based on open dialogue, which is an effective tool in collecting information characterised by an adequate degree of reliability (Farooq and De Villiers, 2017). The interviews were conducted in March and November 2020 using Skype due to restrictions brought about by the COVID-19 pandemic. However, despite the fact that traditional qualitative studies are based on physical meetings, using Skype facilitated the collection of a relevant amount of information (Molinari and de Villiers, 2021).

The secondary data were identified through the analysis of archival data released by Mediolanum and other independent and unrelated sources (Blanc et al., 2019; Martin-Sardesai and Guthrie, 2020). We considered in our research the non-financial reports disclosed in accordance with the Directive 2014/95/EU and the official communications made by Mediolanum and several governing bodies. Furthermore, external sources were analysed to ensure the reliability of the research. Following the study of Hoque (2018, p. 568), we triangulated our data through the cross-evaluation of each information collected during the analysis. Thus, we integrated our data with external information extracted from different, sources such as newspaper articles, interviews and voluntary declarations made by stakeholders (Table 1).

Finally, the data analysis was conducted with NVivo 12, one of the main software programs used for qualitative and mixed-method research. This software allows for the analysis of multiple data sources within the same environment (Jackson and Bazeley, 2020).

\section{Blockchain's idea journey in Mediolanum}

This section presents the findings based on the application of the idea framework (Perry-Smith and Mannucci, 2017) to the rich body of data gathered on Mediolanum's adoption of blockchain. The following subsections represent the main findings of the study regarding the evolutionary pathways adopted by this organisation to publish the first NFD based on blockchain infrastructure.

\subsection{Idea generation}

The implementation of a blockchain-based non-financial report in Mediolanum occurred after intense debate on the role of digitalisation in the banking industry. Prior studies had remarked on the enabling role played by blockchain in the financial sector. Idea generation was favoured both by Mediolanum's interest regarding this type of technological innovation and its involvement within the US consortium called R3. Founded in 2014, $\mathrm{R} 3$ evolved from a bank consortium to an enterprise software firm with the largest blockchain ecosystem in the world. Together with over 350 institutions, R3 pioneered the digital transformation and revolutionised entire industries by digitalising the ways by which firms connect and transact with one another. R3 provided a technological platform that eventually facilitated the transition to blockchain tools: 
' $R 3$ released a platform based on a distributed ledger that allows us to replicate, share and synchronize digital data geographically spread across multiple sites, countries, or institutions.'

As previously mentioned, institutional barriers in the preliminary phases limited the idea generation phrase. Similar issues have been observed in prior studies on innovations in reporting practices. However, Mediolanum mitigated this issue through the introduction of a private blockchain:

'The current scenario is characterised by barriers related to the exigence to combine the benefits generated by blockchain with legal provisions. Thus, we built a private blockchain to be compliant with the Italian system.'

\subsection{Idea elaboration}

Although different processes can be impacted by blockchain, Mediolanum's initial implementation of these systems was in non-financial reporting practices: the bank decided to notarise its NFD to engage with its stakeholders more effectively. The notarisation consists of a protocol to assure the Proof of Ownership (who authored it), Proof of Existence (at a certain time) and Proof of Integrity (no tampering) of the documents (Crosby et al., 2016). Generally, notarisation allows organisations to prepare their NFDs to prove these characteristics using cryptographic hashes without the involvement of independent third parties. These characteristics were the main reasons that encouraged Mediolanum's subsequent adoption of notarisation in its non-financial reporting practices:

'In 2019, we decided to adopt blockchain in non-financial reporting practices. The choice to apply [it] to non-financial reporting was driven by the opportunity to communicate in a more effective way. Although the NFD is prepared on a mandatory basis, we believe in sustainability practices. Our main stakeholders are the clients; thus, we would involve them in our strategies through a more comprehensive communication.'

According to this evidence, internal organisation plays an enabling role in promoting technological innovation. Through the Legislative Decree 254/2016, Italian regulators require firms to assure their NFDs on a mandatory basis. The need to prove the ownership, existence and integrity of documents is realised by the provision of an independent third-party assurance. Notarisation can provide an external assurance of a document that has already been assured. Thus, Mediolanum has established its orientation towards sustainable practices through its choice to notarize its NFD, making it easier for non-expert users to assess the reliability of the non-financial information presented.

'In our opinion, blockchain does not represent a third actor within the dynamics between firms and stakeholders. In fact, the removal of intermediaries is one of the main characteristics of a blockchain systems. Thus, notarisation could be considered a way to mitigate the asymmetric information caused by the different degrees of knowledge.'

\subsection{Championing the idea}


The notarisation of Mediolanum's NFDs is the first attempt to adopt a blockchain system in non-financial reporting practices. Its implementation had both strengths and weaknesses, but the process was encouraged by the bank's technological innovation orientation.

The idea championing process involved few criticisms, especially as there were no predecessors or early adopters to follow. In fact, Mediolanum is widely considered as the first mover within an arena characterised by a low degree of orientation towards innovation:

'Exploring the possible scope of the new frontiers of innovation for Banca Mediolanum included finding technological means to proceed on the path of simplification and dematerialization. With pride, we count ourselves among the first Italian banks to use the "notarization services" offered by blockchain, which means simultaneously ensuring the authentication of the document, along with its immutability and irrefutability, with a view to transparency towards all our stakeholders.' [Chief Innovation, Sustainability and Value Strategy Officer, March 2019]

Mediolanum has chosen to notarize its NFDs on a public blockchain platform, a choice that follows its vision to engage with stakeholders. The main difference between public and private blockchains is the different degree of transparency. Between the two, public blockchains are the most transparent due to the involvement of internal and external stakeholders.

Thus far, Mediolanum's approach towards transparency has been driven by a sense of accountability and not by internal monitoring activities:

'We have used a publicly available blockchain. In our opinion, sustainability requires a high degree of transparency. Thus, blockchain ensures a more effective communication between firms and stakeholders. Furthermore, there are no financial barriers to its adoption. In this sense, the introduction of blockchain systems in non-financial reporting requires only a "political" decision made by the management.'

\subsection{Idea implementation}

Mediolanum's 2018 NFD was the first to be notarised by blockchain. This event received much attention from the media and consulting firms due to its novelty and originality. Mediolanum published the first hash of NFD 2018 on Ethereum to favour the stakeholder engagement activities.

'With the use of Ethereum blockchain and the consequent publication of the hash of the document on the bank's institutional website, Banca Mediolanum has successfully conducted the certification of the immodificability of its NFD. The adoption of this notarisation process is a further confirmation of its vision to honour its commitments, actions and performances in the economic, social and environmental fields known to all stakeholders.' 
The experience was repeated in 2019, and by then, its newly acquired knowledge and expertise allowed Mediolanum to increase its investments in blockchain systems. The organisation confirmed its vision through the publication of the hash on a public platform. In this sense, the notarisation proved to be more than a mere marketing activity developed to act as a first mover in the market:

'In 2019, the activities related to the blockchain continued intensely, where three strands of activity were confirmed that can have impacts on business models in terms of sustainability: dissemination of the culture of innovation dedicated to different types of stakeholders (employees, sales networks, customers/prospects); scouting of solutions, projects and startups capable of exploiting blockchain and distributed ledgers technologies; and participation in the distributed ledgers of Italian and international blockchain and private permissioned implementation projects.' [Non-financial declaration 2019, p. 85]

\section{Discussions}

\subsection{The lesson learned from Mediolanum}

In the last decades, many academics have agreed on the positive externalities related to the disclosure of nonfinancial information on a voluntary basis. Related to this, several studies were conducted through the lens of legitimacy theory, which is a traditional accounting theory used to justify the adoption of best practices by companies (Deegan, 2019; DiMaggio and Powell, 1983). However, the increasing attention paid by companies on sustainability reporting generated criticisms related to the mitigation of the legitimising effect arising from the disclosure of such information. In fact, the existence of different purposes behind the disclosure of nonfinancial information negatively impacted stakeholders' trust. Thus, virtuous companies were penalised by the entrance of companies driven by the need to comply with legal requirements (Doni et al., 2019; KPMG, 2020). Building on this preliminary evidence, virtuous companies have begun to innovate their reports through the identification of new features. Many organisations started to enhance their accountability practices using websites, social media and digital platforms (Lodhia et al., 2020; Merkl-Davies and Brennan, 2017). However, the road towards the effective digitalisation of sustainability reporting is still characterised by many opportunities related to the rapid growth of new technologies. In particular, many academics have highlighted the opportunities connected to blockchains as an emerging tool in accounting and auditing processes (Dai and Vasarhelyi, 2017).

Regarding blockchain, many scholars and practitioners have also discussed its potential implementation in financial accounting and auditing processes (Deloitte, 2020; Mancini et al., 2021). However, current knowledge on blockchain's potentialities in sustainability reporting is fragmented and scarce. Thus, the Mediolanum case represents one of the first attempts to discuss how blockchain can enhance sustainability reporting. 
The NFD's notarisation was driven by the need to emphasise Mediolanum's sustainable and ethical orientation. In fact, information on the effects of the transposition of the Directive 2014/95/EU is quite limited because the organisation is a first mover in sustainability reporting. Thus, the technological innovation adopted by Mediolanum's preparers arose not in response to bureaucracy but from an internal stimulus to favour the stakeholder engagement processes. Unlike traditional third-party independent assurance, the notarisation was non-local, secure and auditable and has smart execution (Saberi et al., 2019). Thus, such notarisation avoided the risks of a 'tick-box approach' used by some enterprises to comply with the law without a real orientation towards sustainable practices (Ackers and Eccles, 2015). Therefore, notarisation is a legitimation tool that can signal Mediolanum's orientation towards sustainable development and business ethics in a more effective way.

Furthermore, this analysis contributes to a better understanding of the enabling factors that positively impact blockchain adoption (Table 3). Building on theoretical and practical paradigms (Perry-Smith, 2014; Saberi et al., 2019), this work provides new insights into the trade-off between the exigence to comply with the law and an orientation towards technological innovation. In particular, the analysis reveals that Mediolanum managed to overcome the barriers through a proactive approach. Starting from idea elaboration, Mediolanum acted as a first mover and adopted strategies based on the implementation of new practices. Furthermore, the bank operated through an open innovation approach to integrate the contributions of R3 and other external actors into its process. However, as shown by Table 1, the most important factor is the recognition of stakeholders' central role. Despite the absence of pressure from regulators, the journey towards the first notarisation of an NFD involved continuous engagement with the stakeholders. In this sense, notarisation served as an extension of the activities implemented by Mediolanum prior to the transposition of the Directive 2014/95/EU.

\section{Please Insert Table 3}

\subsection{Notarisation in accounting and auditing: a practical framework}

Developing business relationships characterised by an adequate degree of trust represents a critical issue for companies. In a complex scenario marked by the proliferation of non-financial information, engaging with stakeholders requires the implementation of new practices characterised by reliability and traceability (Dumay et al., 2015; Jackson et al., 2020). Furthermore, the reliability of such information is negatively impacted by the wide adoption of the ISAE3000, which is a controversial standard due to its 'limited approach' (Simnett, 2012). In fact, external auditors are called to judge the reliability of documents that lack many details. Furthermore, several studies have discussed the limits caused by the monetary relationships between auditors and firms. Although this relationship theoretically does not impact the auditing activities, some studies have provided empirical evidence of numerous restatements after the assurors' replacement (Cho et al., 2015; Sheldon and Jenkins, 2020). Non-expert users are unable to evaluate the reliability of the information provided by firms.

In this regard, blockchain is an effective tool to mitigate the asymmetries between companies and stakeholders. The 'irrefutability' of the information published on blockchain can contribute to the pursuit of this ambitious 
goal. In detail, firms cannot replace or revise their commitments after notarisation because blocks have already certified the reliability of the hash (Figure 1). Thus, stakeholders can evaluate the non-financial performance disclosed by a company without distortion caused by unethical mechanisms. Furthermore, notarisation can be part of a continuous auditing paradigm, which involves monitoring the processes on a day-by-day basis. In fact, the reliability of the included documents is certified by each block of blockchain. Thus, firms are exposed to continuous reputation risks, because each member of the chain can evaluate the quality of the stored information. Furthermore, each member of the blockchain is motivated to certify only reliable documents, because the value of a blockchain is based on each node's quality.

Please Insert Figure 1

In light of this evidence and following the theoretical paradigm of legitimacy theory (Deegan, 2002), experimentation with blockchain-based assurance practices cannot be implemented without a real orientation towards ethical paradigms. Unlike other blockchain-based tools, notarisation has certain characteristics that do not impact organisational dynamics. On the one hand, some firms are not interested in adopting these practices to be compliant with legal requirements. This evidence is central within the current scenario due to the proliferation of new forms of regulations regarding mandatory non-financial reporting (Dumay et al., 2015). On the other hand, there are no direct connections between notarisation and firm performance. In fact, the reduction of transaction costs, which is typically a key benefit of notarisation, does not occur due to the legal provisions that explicitly require third-party assurance (Venturelli and Pizzi, 2020). Instead, the main benefit of certifying documents with blockchain is the opportunity to engage with stakeholders more effectively and without barriers caused by the adoption of technical language and reports that provide little information.

\section{Conclusion}

Blockchain systems are likely to develop rapidly in the coming years. In fact, policymakers, practitioners and companies have already started to discuss the potential of this innovative tool. However, despite their great interest, no consolidated field of study on blockchains has emerged. Scientific management and accounting knowledge about blockchain is rare due to a lack of expertise on the topic and its novelty. In addition, the tool's flexibility creates a challenge in developing an independent research area due to the high degree of contamination between fields.

With regard to business and management studies, accounting and auditing scholars have started to include blockchain in their agenda (Moll and Yigitbasioglu, 2019; Schmitz and Leoni, 2019). However, resistance to innovations in the accounting profession, which can be attributed to the lack of managerial evidence regarding the possible impacts of blockchain on organisations, has slowed the growth of a field with great potential.

The current research contributes to the collection of novel and original insights into the relationship between sustainability reporting and blockchain. In fact, despite the central role played by blockchain in ongoing 
debates in this field, the main accounting studies on its implementation are related to financial reporting and auditing (Dai and Vasarhelyi, 2017; Mancini et al., 2021). Thus, by using a multidimensional approach based on the integration of the frameworks proposed by Perry-Smith and Mannucci (2017) and Saberi et al. (2019), the present paper contributes to the debate by offering theoretical, managerial and policy implications of blockchain's integration into sustainability reporting.

The theoretical implications are represented by the new insights into the signalling effects related to the voluntary adoption of blockchain. Following the theoretical reflection proposed by DiMaggio and Powell (1983), the analysis in the current work underlined the opportunity for virtuous firms to signal their orientation towards sustainable and ethical practices using an innovative legitimacy tool. In fact, the voluntary adoption of blockchain can mitigate the negative effects related to the competitors' late adoption of sustainability reports. In this sense, notarisation could limit the risks related to the adoption of isomorphisms by these competitors. Furthermore, the analysis extends the scientific knowledge on blockchain through novel insights about the integration of new technologies in sustainability reporting, thereby representing a standalone topic in accounting and management studies (Mancini et al., 2021).

Regarding the managerial implications, the lesson learned from Mediolanum is that there is an opportunity to adopt blockchain in sustainability reporting. In a current scenario characterised by an increasing awareness about the disclosure of non-financial information, managers could consider using blockchain to signal their distinct orientation towards sustainability. Traditional tools, such as the adoption of the GRI, or the provision of an external assurance, may lose their legitimacy due to their wide adoption. As an alternative, notarisation could be an effective tool to engage with stakeholders in a more effective way.

The policy implications are related to the recent debates about the revision of the Directive 2014/95/EU, which revealed that the regulation's main impacts can be summarised in a quantitative increase of the overall number of reports disclosed annually. As evidenced by many international surveys, only a limited number of companies revised their business models after its transposition. In this sense, encouraging companies to legitimate their practices through voluntary tools could represent a strategic innovation to move from a bureaucratic to a more strategic approach towards sustainability reporting.

Finally, as in every study, the present research is affected by limitations. One of the main limitations is its analysis of an institutional setting characterised by external pressures made by regulators. Related to this, future research can fill the scientific gap related to reducing transactional costs in the face of voluntary nonfinancial reporting practices. In addition, our findings could be extended to a larger sample using quantitative analysis instead of a qualitative approach. 


\section{References}

Ackers, B. and Eccles, N.S. (2015), 'Mandatory corporate social responsibility assurance practices: The case of king iii in South Africa', Accounting, Auditing and Accountability Journal, Emerald Group Publishing Ltd., Vol. 28 No. 4, pp. 515-550.

Adams, C. and Narayanan, V.-. (2010), 'The "standardization" of sustainability reporting', Sustainability Accounting and Accountability, Routledge, pp. 89-104.

Ahluwalia, S., Mahto, R. V and Guerrero, M. (2020), 'Blockchain technology and startup financing: A transaction cost economics perspective', Technological Forecasting and Social Change, Vol. 151, available at:https://doi.org/10.1016/j.techfore.2019.119854.

Al-Htaybat, K. and von Alberti-Alhtaybat, L. (2018), 'Integrated thinking leading to integrated reporting: case study insights from a global player', Accounting, Auditing and Accountability Journal, Emerald Group Publishing Ltd., Vol. 31 No. 5, pp. 1435-1460.

Bartolacci, F., Caputo, A., Fradeani, A. and Soverchia, M. (2020), 'Twenty Years of XBRL: What We Know and Where We Are Going', Meditari Accountancy Research, Emerald, available at:https://doi.org/10.1108/MEDAR-04-2020-0846.

Bebbington, J., Kirk, E.A. and Larrinaga, C. (2012), 'The production of normativity: A comparison of reporting regimes in Spain and the UK', Accounting, Organizations and Society, Elsevier Ltd, Vol. 37 No. 2, pp. 78-94.

Bible, W., Raphael, J., Riviello, M., Taylor, P. and Valiente, I.O. (2017), 'Blockchain technology and its potential impact on the audit and assurance profession', CPA Canada, AICPA, pp. 1-28.

Blanc, R., Cho, C.H., Sopt, J. and Branco, M.C. (2019), 'Disclosure Responses to a Corruption Scandal: The Case of Siemens AG', Journal of Business Ethics, Springer Netherlands, Vol. 156 No. 2, pp. 545-561.

Cai, C.W. (2018), 'Disruption of financial intermediation by FinTech: a review on crowdfunding and blockchain', Accounting \& Finance, Blackwell Publishing, Vol. 58 No. 4, pp. 965-992.

Caputo, F., Leopizzi, R., Pizzi, S. and Milone, V. (2019), 'The Non-Financial Reporting Harmonization in Europe: Evolutionary Pathways Related to the Transposition of the Directive 95/2014/EU within the Italian Context', Sustainability, Vol. 12 No. 1, p. 92.

Chiu, V., Liu, Q., Muehlmann, B. and Baldwin, A.A. (2019), 'A bibliometric analysis of accounting information systems journals and their emerging technologies contributions', International Journal of Accounting Information Systems, Vol. 32, pp. 24-43.

Cho, C.H., Michelon, G., Patten, D.M. and Roberts, R.W. (2015), 'CSR report assurance in the USA : an empirical investigation of determinants and effects', available at:https://doi.org/10.1108/SAMPJ-01- 
2014-0003.

Cordery, C.J., Fowler, C.J. and Mustafa, K. (2011), 'A solution looking for a problem: factors associated with the non-adoption of XBRL', Pacific Accounting Review, Emerald Group Publishing Ltd., Vol. 23 No. 1, pp. 69-88.

Corvino, A., Doni, F. and Martini, S.B. (2020), 'Corporate governance, integrated reporting and environmental disclosure: Evidence from the South African context', Sustainability (Switzerland), Vol. 12 No. 12 , p. 4820.

Crosby, M., Nachiappan, Pattanayak, P., Sanjeev, V. and Kalyanaraman, V. (2016), BlockChain Technology: Beyond Bitcoin.

Dai, J. and Vasarhelyi, M.A. (2017), 'Toward blockchain-based accounting and assurance', Journal of Information Systems, American Accounting Association, Vol. 31 No. 3, pp. 5-21.

Deegan, C. (2002), 'Introduction: The legitimising effect of social and environmental disclosures - a theoretical foundation', Accounting, Auditing \& Accountability Journal, 1 August.

Deegan, C.M. (2019), 'Legitimacy theory: Despite its enduring popularity and contribution, time is right for a necessary makeover', Accounting, Auditing and Accountability Journal, Emerald Group Publishing Ltd., Vol. 32 No. 8, pp. 2307-2329.

Deloitte. (2019a), Osservatorio Nazionale Sulla Rendicontazione Non Finanziaria Ex D . Lgs . 254 / 20161 ${ }^{\circ}$ Report | Ottobre 2018 Osservatorio Nazionale Sulla Rendicontazione Non Finanziaria Report 2018.

Deloitte. (2019b), Deloitte's 2019 Global Blockchain Survey.

Deloitte. (2020), Global Blockchain Survey 2019, available at: https://www2.deloitte.com/it/it/pages/financial-services/articles/global-blockchain-survey---deloitteitaly---financial-services.html (accessed 14 July 2021).

DiMaggio, P.J. and Powell, W.W. (1983), 'The iron cage revisited institutional isomorphism and collective rationality in organizational fields', American Sociological Review.

Diouf, D. and Boiral, O. (2017), 'The quality of sustainability reports and impression management: A stakeholder perspective', Accounting, Auditing and Accountability Journal, Emerald Group Publishing Ltd., Vol. 30 No. 3, pp. 643-667.

Doni, F., Bianchi Martini, S., Corvino, A. and Mazzoni, M. (2019), 'Voluntary versus mandatory nonfinancial disclosure', Meditari Accountancy Research, Emerald Group Publishing Ltd., Vol. 28 No. 5, pp. 781-802.

Donohue, N. (2018), 'The Truth Machine: The Blockchain and the Future of Everything.', Booklist, Vol. 114 No. 11, pp. 7-8. 
Dumay, J., Frost, G. and Beck, C. (2015), 'Material legitimacy: Blending organisational and stakeholder concerns through non-financial information disclosures', Journal of Accounting and Organizational Change, Emerald Group Publishing Ltd., Vol. 11 No. 1, pp. 2-23.

Dumay, J., La Torre, M. and Farneti, F. (2019), 'Developing trust through stewardship: Implications for intellectual capital, integrated reporting, and the EU Directive 2014/95/EU', Journal of Intellectual Capital, Emerald Group Publishing Ltd., Vol. 20 No. 1, pp. 11-39.

Durocher, S., Fortin, A. and Côté, L. (2007), 'Users' participation in the accounting standard-setting process: A theory-building study', Accounting, Organizations and Society, Vol. 32 No. 1-2, pp. 29-59.

European Commission. (2019), Consultation Strategy for the Revision of the Non - Financial Reporting Directive.

European Commission. (2020), 'Revision of the Non-Financial Reporting Directive'.

Farooq, M.B. and De Villiers, C. (2017), 'Telephonic qualitative research interviews: When to consider them and how to do them', Meditari Accountancy Research, Vol. 25 No. 2, pp. 291-316.

Forbes. (2019), 'Blockchain, Italia: le 10 aziende che usano la "catena dei blocchi” da Barilla a Mediolanum', 25 July, available at: https://forbes.it/2019/07/25/blockchain-italia-10-aziende-italianeche-usano-la-catena-de-blocchi/ (accessed 9 October 2020).

Hart, O. and Zingales, L. (2017), 'Companies should maximize shareholder welfare not market value', ECGI-Finance Working Paper, No. 521.

Helliar, C. V., Crawford, L., Rocca, L., Teodori, C. and Veneziani, M. (2020), 'Permissionless and permissioned blockchain diffusion', International Journal of Information Management, Elsevier, Vol. 54 No. October 2019, p. 102136.

Hinkes, C. and Peter, G. (2020), 'Traceability matters: A conceptual framework for deforestation-free supply chains applied to soy certification', Sustainability Accounting, Management and Policy Journal, Emerald Publishing Limited, Vol. 11 No. 7, pp. 1159-1187.

Hinkin, T.R., Tracey, J.B. and Enz, C.A. (1997), ‘Scale construction: Developing reliable and valid measurement instruments', edited by SAGEJournal of Hospitality \& Tourism Research, SAGE Publications Inc., Thousand Oaks, Vol. 21 No. 1, pp. 100-120.

Hoque, Z. (2018), Methodological Issues in Accounting Research: Second Edition.

Hughes, L., Dwivedi, Y.K., Misra, S.K., Rana, N.P., Raghavan, V. and Akella, V. (2019), 'Blockchain research, practice and policy: Applications, benefits, limitations, emerging research themes and research agenda', International Journal of Information Management, Elsevier, Vol. 49 No. February, pp. 114-129. 
IFAC. (2019), 'Trends in Disclosing Non-Financial Information', available at: https://www.ifac.org/knowledge-gateway/discussion/trends-disclosing-non-financial-information (accessed 8 May 2020).

Jackson, G., Bartosch, J., Avetisyan, E., Kinderman, D. and Knudsen, J.S. (2020), 'Mandatory Non-financial Disclosure and Its Influence on CSR: An International Comparison', Journal of Business Ethics, Springer Netherlands, Vol. 162 No. 2, pp. 323-342.

Jackson, K. and Bazeley, P. (2020), Qualitative Data Analysis with NVivo, Third Edit., SAGE.

Karajovic, M., Kim, H.M. and Laskowski, M. (2019), 'Thinking Outside the Block: Projected Phases of Blockchain Integration in the Accounting Industry', Australian Accounting Review, Blackwell Publishing Ltd, Vol. 29 No. 2, pp. 319-330.

Korca, B., Costa, E. and Farneti, F. (2021), 'From voluntary to mandatory non-financial disclosure following Directive 2014/95/EU: an Italian case study', Accounting in Europe, Routledge, pp. 1-25.

KPMG. (2017), The KPMG Survey of Corporate Responsibility Reporting 2017, available at: www.kpmg.com/crreporting (accessed 30 November 2019).

KPMG. (2020), The Time Has Come: The KPMG Survey of Sustainability Reporting 2020, available at: https://home.kpmg/xx/en/home/insights/2020/11/the-time-has-come-survey-of-sustainabilityreporting.html (accessed 5 December 2020).

Lee, B. and Humphreys, C. (2017), 'Case studies in accounting research', in Hoque, Z., Parker, L., Covaleski, M. and Haynes, K. (Eds.), The Routledge Companion to Qualitative Accounting Research Methods, 1st ed., Routledge, pp. 163-183.

Liff, R. and Wahlström, G. (2018), 'Failed crisis communication: the Northern Rock Bank case', Accounting, Auditing and Accountability Journal, Emerald Group Publishing Ltd., Vol. 31 No. 1, pp. $237-260$.

Lodhia, S., Kaur, A. and Stone, G. (2020), 'The use of social media as a legitimation tool for sustainability reporting: A study of the top 50 Australian Stock Exchange (ASX) listed companies', Meditari Accountancy Research, Emerald Group Publishing Ltd., available at:https://doi.org/10.1108/MEDAR09-2019-0566.

Lombardi, R., de Villiers, C., Moscariello, N. and Pizzo, M. (2021), 'The disruption of blockchain in auditing - a systematic literature review and an agenda for future research', Accounting, Auditing \&amp; Accountability Journal, Emerald Publishing Limited, available at:https://doi.org/10.1108/AAAJ-10-2020-4992.

Lumineau, F. and Oliveira, N. (2017), 'A Pluralistic Perspective to Overcome Major Blind Spots in Research on Interorganizational Relationships', Https://Doi.Org/10.5465/Annals.2016.0033, Academy of 
Management AnnalsBriarcliff Manor, NY, Vol. 12 No. 1, pp. 440-465.

Mancini, D., Lombardi, R. and Tavana, M. (2021), 'Four research pathways for understanding the role of smart technologies in accounting', Meditari Accountancy Research, Vol. ahead-of-p No. ahead-ofprint, available at:https://doi.org/10.1108/medar-03-2021-1258.

March, J.G. (1987), ‘Ambiguity and accounting: The elusive link between information and decision making', Accounting, Organizations and Society, Pergamon, Vol. 12 No. 2, pp. 153-168.

Martin-Sardesai, A. and Guthrie, J. (2020), 'Social report innovation: evidence from a major Italian bank 2007-2012', Meditari Accountancy Research, Vol. 28 No. 1, pp. 72-88.

Mediolanum. (2021), 'La Sostenibilità di Mediolanum ', available at: https://www.youtube.com/watch?v=pvgwI5Og6xQ\&list=PLcJ0EUyICt0NNUAyg3bIti18V4XTJGA5\&index=2 (accessed 11 October 2021).

Merkl-Davies, D.M. and Brennan, N.M. (2017), 'A theoretical framework of external accounting communication: Research perspectives, traditions, and theories', Accounting, Auditing and Accountability Journal, Emerald Group Publishing Ltd., Vol. 30 No. 2, pp. 433-469.

Molinari, M. and de Villiers, C. (2021), 'Qualitative accounting research in the time of COVID-19changes, challenges and opportunities', Pacific Accounting Review, available at:https://doi.org/10.1108/PAR-09-2020-0176.

Moll, J. and Yigitbasioglu, O. (2019), 'The role of internet-related technologies in shaping the work of accountants: New directions for accounting research', British Accounting Review, Elsevier Ltd, Vol. 51 No. 6, p. 100833.

Nakamoto, S. (2008), 'Bitcoin: A Peer-toPeer Electronic Cash System', pp. 1-9.

Nicolo, G., Zanellato, G., Manes-Rossi, F. and Tiron-Tudor, A. (2020), 'Corporate reporting metamorphosis: empirical findings from state-owned enterprises', Public Money and Management, Taylor \& Francis, Vol. 0 No. 0, pp. 1-10.

Parker, L.D. (2012), 'Qualitative management accounting research: Assessing deliverables and relevance', Critical Perspectives on Accounting, Academic Press, Vol. 23 No. 1, pp. 54-70.

Perry-Smith, J.-E.U.H.P. (2014), 'From Creativity To Innovation: the Social Network Drivers of the Four Phases of the Idea Journey', Academy of Management Review, Vol. Original M.

Perry-Smith, J.E. and Mannucci, P.V. (2017), 'From creativity to innovation: The social network drivers of the four phases of the idea journey', Academy of Management Review, Academy of Management, Vol. 42 No. 1, pp. 53-79.

Pizzi, S., Rosati, F. and Venturelli, A. (2021), 'The determinants of business contribution to the 2030 
Agenda: Introducing the SDG Reporting Score', Business Strategy and the Environment, Vol. 30 No. 1, pp. 404-421.

Pizzi, S., Venturelli, A. and Caputo, F. (2021), “The “comply-or-explain” principle in directive 95/2014/EU. A rhetorical analysis of Italian PIEs', Sustainability Accounting, Management and Policy Journal, Emerald Group Publishing Ltd., Vol. 12 No. 1, pp. 30-50.

Plec, E. and Pettenger, M. (2012), 'Greenwashing consumption: The didactic framing of ExxonMobil's energy solutions', Environmental Communication, Vol. 6 No. 4, pp. 459-476.

PWC. (2018), PwC Global Blockchain Survey, available at: https://www.pwc.com/gx/en/issues/blockchain/blockchain-in-business.html (accessed 13 June 2020).

Rinaldi, L., Unerman, J. and de Villiers, C. (2018), 'Evaluating the integrated reporting journey: insights, gaps and agendas for future research', Accounting, Auditing and Accountability Journal, Emerald Group Publishing Ltd., Vol. 31 No. 5, pp. 1294-1318.

Saberi, S., Kouhizadeh, M., Sarkis, J. and Shen, L. (2019), 'Blockchain technology and its relationships to sustainable supply chain management', International Journal of Production Research, Taylor and Francis Ltd., Vol. 57 No. 7, pp. 2117-2135.

Sandberg, J., Studies, M.A.-J. of M. and 2021, undefined. (2020), 'Meanings of theory: Clarifying theory through typification', Wiley Online Library, Blackwell Publishing Ltd, Vol. 58 No. 2, pp. 487-516.

Schmitz, J. and Leoni, G. (2019), 'Accounting and Auditing at the Time of Blockchain Technology: A Research Agenda', Australian Accounting Review, Blackwell Publishing Ltd, Vol. 29 No. 2, pp. 331342.

Sheel, A. and Nath, V. (2019), 'Effect of blockchain technology adoption on supply chain adaptability, agility, alignment and performance', Management Research Review, Emerald Group Publishing Ltd., Vol. 42 No. 12, pp. 1353-1374.

Sheldon, M.D. and Jenkins, J.G. (2020), 'The influence of firm performance and (level of) assurance on the believability of management's environmental report', Accounting, Auditing and Accountability Journal, Emerald Publishing Limited, Vol. 33 No. 3, pp. 501-528.

Siano, A., Vollero, A., Conte, F. and Amabile, S. (2017), “More than words": Expanding the taxonomy of greenwashing after the Volkswagen scandal', Journal of Business Research, Elsevier Inc., Vol. 71, pp. $27-37$.

Simnett, R. (2012), 'Assurance of sustainability reports: Revision of ISAE 3000 and associated research opportunities', Sustainability Accounting, Management and Policy Journal, Emerald Group Publishing Limited, Vol. 3 No. 1, pp. 89-98. 
Simnett, R., Huggins, A.L., Simnett, R. and Huggins, A.L. (2015), 'Integrated reporting and assurance : where can research add value ?', available at:https://doi.org/10.1108/SAMPJ-09-2014-0053.

Steurer, R., Martinuzzi, A. and Margula, S. (2012), 'Public Policies on CSR in Europe: Themes, Instruments, and Regional Differences', Corporate Social Responsibility and Environmental Management, Vol. 19 No. 4, pp. 206-227.

Storbeck, O. and McCrum, D. (2020), 'Wirecard's deceit went beyond its fraudulent Asian operations', Financial Times, September.

Stubbs, W. and Higgins, C. (2018), 'Stakeholders' Perspectives on the Role of Regulatory Reform in Integrated Reporting', Journal of Business Ethics, Springer Netherlands, Vol. 147 No. 3, pp. 489-508.

Sutton, S.G., Reinking, J. and Vicky, A. (2011), 'On the use of grounded theory as a basis for research on strategic and emerging technologies in accounting', Journal of Emerging Technologies in Accounting, Allen Press, Vol. 8 No. 1, pp. 45-63.

Tandon, A., Kaur, P., Mäntymäki, M. and Dhir, A. (2021), 'Blockchain applications in management: A bibliometric analysis and literature review', Technological Forecasting and Social Change, NorthHolland, Vol. 166, p. 120649.

Tapscott, D. and Tapscott, A. (2016), Blockchain Revolution: How the Technology behind Bitcoin and Other Cryptocurrencies Is Changing the World, Penguin Random House, available at: https://www.penguinrandomhouse.com/books/531126/blockchain-revolution-by-don-tapscott-and-alextapscott/ (accessed 13 June 2020).

The Alliance for Corporate Transparency. (2020), 2019 Research Report: An Analysis of the Sustainability Reports of 1000 Companies Pursuant to the EU Non-Financial Reporting Directive.

La Torre, M., Sabelfeld, S., Blomkvist, M. and Dumay, J. (2020), 'Rebuilding trust: sustainability and nonfinancial reporting and the European Union regulation', Meditari Accountancy Research, Emerald Group Publishing Ltd., Vol. 28 No. August, pp. 701-725.

La Torre, M., Sabelfeld, S., Blomkvist, M., Tarquinio, L. and Dumay, J. (2018), ‘Harmonising non-financial reporting regulation in Europe: Practical forces and projections for future research', Meditari Accountancy Research, Emerald Group Publishing Ltd., Vol. 26 No. 4, pp. 598-621.

Tucker, B.P. (2020), 'Jumping through hoops: publishing interview-based management accounting research', Accounting, Auditing and Accountability Journal, Emerald Group Publishing Ltd., available at:https://doi.org/10.1108/AAAJ-08-2020-4737.

Di Tullio, P., Valentinetti, D., Nielsen, C. and Rea, M.A. (2019), 'In search of legitimacy: a semiotic analysis of business model disclosure practices', Meditari Accountancy Research, Emerald Group Publishing Ltd., Vol. 28 No. 5, pp. 863-887. 
Unerman, J., Bebbington, J. and O'dwyer, B. (2018), ‘Corporate reporting and accounting for externalities', Accounting and Business Research, Taylor \& Francis, Vol. 48 No. 5, pp. 497-522.

Di Vaio, A. and Varriale, L. (2020), 'Blockchain technology in supply chain management for sustainable performance: Evidence from the airport industry', International Journal of Information Management, Elsevier, Vol. 52 No. October 2019, p. 102014.

Venturelli, A., Caputo, F., Leopizzi, R. and Pizzi, S. (2019), 'The state of art of corporate social disclosure before the introduction of non-financial reporting directive: a cross country analysis', Social Responsibility Journal, Emerald Group Publishing Ltd., Vol. 15 No. 4, pp. 409-423.

Venturelli, A. and Pizzi, S. (2020), 'What Drives the Level of Non-financial Assurance in PIEs? Empirical Evidence on the European Firms Listed on Forbes 2000', in Del Baldo, M., Dillard, J., Baldarelli, M.G. and Ciambotti, M. (Eds.), Accounting, Accountability \& Society, Springer International Publishing, pp. 245-265.

de Villiers, C., Kuruppu, S. and Dissanayake, D. (2020), 'A (new) role for business - Promoting the United Nations' Sustainable Development Goals through the internet-of-things and blockchain technology', Journal of Business Research, available at:https://doi.org/10.1016/j.jbusres.2020.11.066.

Wamba, S.F. and Queiroz, M.M. (2020), 'Blockchain in the operations and supply chain management: Benefits, challenges and future research opportunities', International Journal of Information Management, Vol. 52, available at:https://doi.org/10.1016/j.ijinfomgt.2019.102064.

Wang, Y., Han, J.H. and Beynon-Davies, P. (2019), 'Understanding blockchain technology for future supply chains: a systematic literature review and research agenda', Supply Chain Management, Emerald Group Publishing Ltd., 14 January.

Wong, L.W., Leong, L.Y., Hew, J.J., Tan, G.W.H. and Ooi, K.B. (2020), 'Time to seize the digital evolution: Adoption of blockchain in operations and supply chain management among Malaysian SMEs', International Journal of Information Management, Elsevier, Vol. 52 No. June 2019, p. 101997.

Yin, R.K. (2012), 'Case study methods.', APA Handbook of Research Methods in Psychology, Vol 2: Research Designs: Quantitative, Qualitative, Neuropsychological, and Biological., American Psychological Association, Washington, pp. 141-155. 


\begin{tabular}{|l|l|l|}
\hline Source of evidence & Description & Perspective \\
\hline Press releases & $\begin{array}{l}\text { 2 Press releases published by } \\
\text { Mediolanum }\end{array}$ & Internal \\
\hline Non-financial Declarations & $\begin{array}{l}\text { 3 non-financial declarations published } \\
\text { during the period 2017-2019 }\end{array}$ & Internal \\
\hline Newspapers \& Magazines & $\begin{array}{l}\text { 34 Articles published in magazines and } \\
\text { newspapers }\end{array}$ & External \\
\hline
\end{tabular}


Table 2 Barriers to blockchain technology adoption in non-financial reporting. Our elaboration on the model proposed by Saberi et al. (2019a)

\begin{tabular}{|c|c|}
\hline Barriers & Items \\
\hline Intra-organizational barriers & $\begin{array}{l}\text { - } \text { Financial constraints } \\
\text { - } \text { Lack of management commitment and support } \\
\text { - } \quad \text { Lack of new organizational policies for using } \\
\text { technologies } \\
\text { - Lack of knowledge and expertise } \\
\text { - } \text { Difficulty in changing organizational culture } \\
\text { - Hesitation to convert to new systems } \\
\text { - Lack of tools for blockchain technology } \\
\text { implementation }\end{array}$ \\
\hline Inter-organizational barriers &  \\
\hline Systems-related barriers & 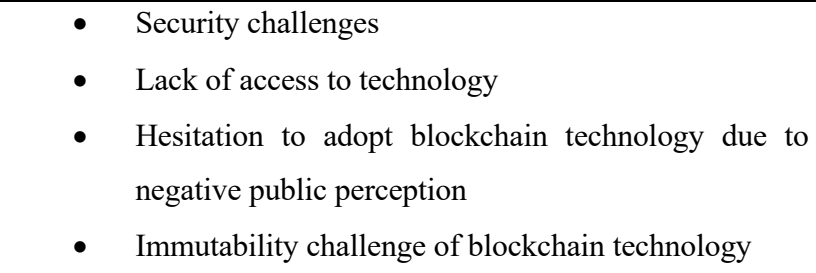 \\
\hline External barriers & $\begin{array}{ll}\text { - } & \text { Lack of governmental policies } \\
\text { - } & \text { Market competition and uncertainly } \\
\text { - } & \text { Lack of external stakeholder involvement } \\
\text { - } & \text { Lack of industry involvement in ethical and safe } \\
\text { - } & \text { Lack of rewards and encouragement programs }\end{array}$ \\
\hline
\end{tabular}


Table 3 Implementation of blockchain in non-financial reporting. Our elaboration on Perry-Smith and Mannucci (2017) and Saberi et al. (2019b)

\begin{tabular}{lcccc}
\hline & $\begin{array}{c}\text { Intra- } \\
\text { organizational }\end{array}$ & Inter-organizational & System-related & External \\
\hline Idea Generation & $\begin{array}{c}\text { Training } \\
\text { activities }\end{array}$ & $\begin{array}{c}\text { Stakeholder } \\
\text { pressures }\end{array}$ & Outsourcing & Competition dynamics \\
Idea Elaboration & $\begin{array}{c}\text { Scenario } \\
\text { analysis }\end{array}$ & Increased & Mandatory non-financial reporting & Stakeholder \\
& transparency & assurance & engagement \\
Championing Idea & meetings & Adoption of public & First mover in notarization & Stakeholder orientation \\
& blockchain & Culture of & Involvement in new projects & Rewarded by external \\
Idea Elaboration & investments & innovation & & stakeholders
\end{tabular}


Figure 1 Non-financial reporting's notarization.
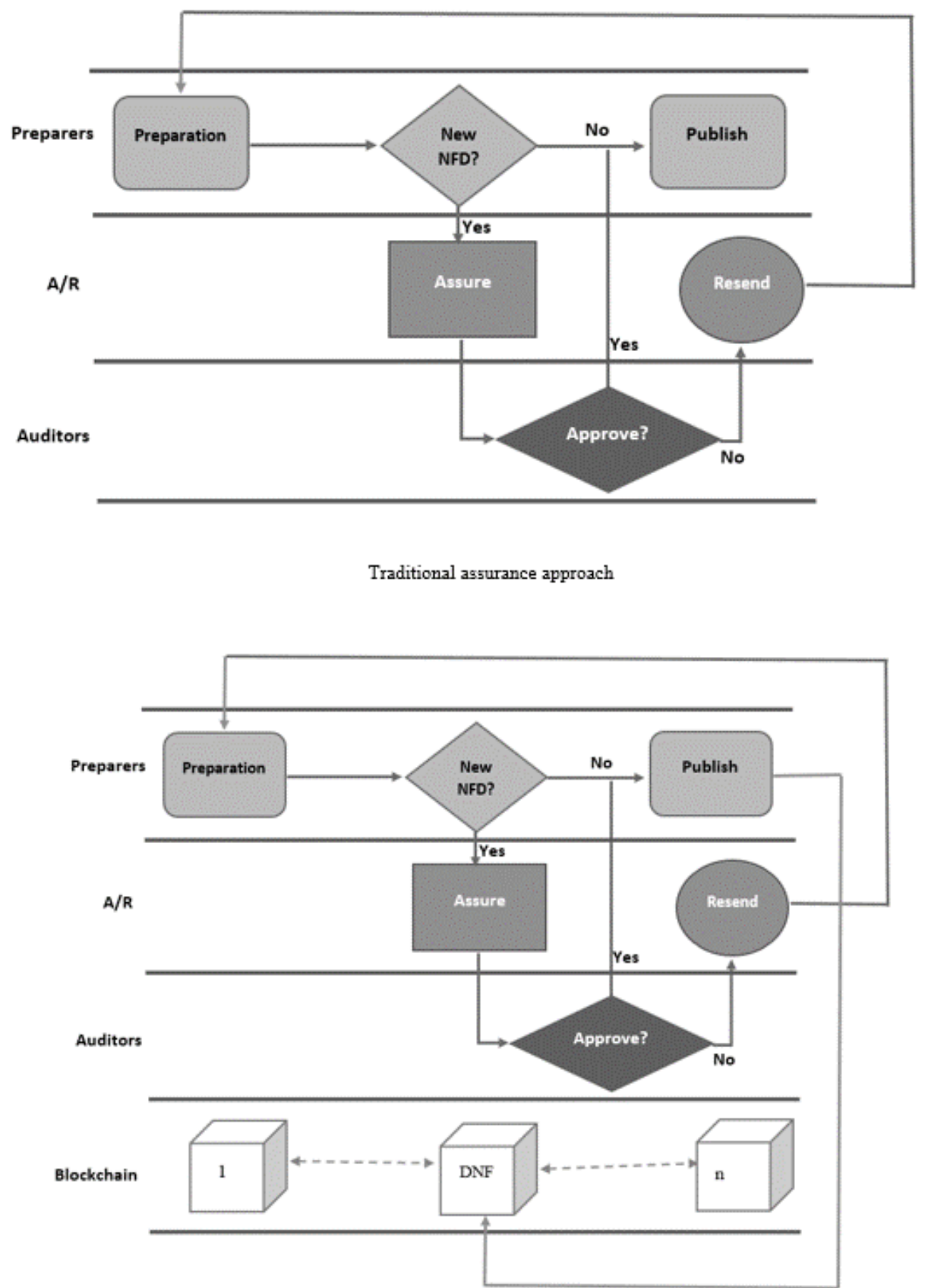

Blockchain-based assurance 